\title{
Improving Pre-service Science Teachers' Performance in Nomenclature of Aliphatic Hydrocarbons using Flipped Classroom Instruction
}

\author{
Emmanuel Kyame Oppong ${ }^{1 *}$, Francis Quansah², Soloman Boachie ${ }^{3}$ \\ 'Department of Science Education, University of Education, Winneba, Ghana, ${ }^{2}$ Department of Science, Foso College of Education, Assin Foso, \\ Ghana, ${ }^{3}$ Department of Science, St. Ambrose College of Education, Dorma, Ghana
}

*Corresponding Author: emmakyameoppong@yahoo.com

\section{ABSTRACT}

This paper reports on a study that sought to improve pre-service science teachers' performance in the International Union of Pure and Applied Chemistry (IUPAC) nomenclature of aliphatic hydrocarbons using flipped classroom instructional approach (FCA). The study employed a single group pre- and post-test action research design. The sample size consisted of forty-five (45) $1^{\text {st }}$ year pre-service science teachers of Foso College of Education (FOSCO) taking the Introduction to Organic Chemistry I course. A purposive sampling technique of the non-probability sampling procedure was used to select the pre-service science teachers in an intact class. Pre-Service Science Teachers' Hydrocarbon Concept Diagnostic Test and Pre-Service Science Teachers' Hydrocarbon Concept Achievement Test were the research instruments used to collect the data. The instruments were pilot-tested at St. Ambrose College of Education and the reliability index found to be 0.75 for the pre-intervention test and 0.78 for the post-intervention test. After 9 weeks of engaging pre-service science teachers through in-class face-to-face activities and out-of-class online interaction of teaching and learning IUPAC nomenclature of aliphatic hydrocarbons, it came to light that pre-service science teachers' performance had improved greatly after they have been exposed to FCA as an intervention strategy. It was recommended that College of Education chemistry tutors should adopt newly interactive and innovative instructional strategies such as the FCA so as to help pre-service science teachers overcome challenging chemical concepts like the IUPAC nomenclature and other difficult chemistry concepts in and out of colleges or schools.

KEY WORDS: Performance; pre-service teachers; aliphatic hydrocarbons; flipped classroom; instructional approach

\section{INTRODUCTION}

J $\mathrm{n}$ recent decades, student-centered learning approaches have shown great promise in helping students learn meaningfully (Paristiowati et al., 2017) and that, this student-centered approach is known to have overarching power over the traditional teacher-centered approach. This has resulted in a crusade for its usage as a means of educational instruction especially in higher educational institutions. In fact, the past decade has witnessed massive advocacy for use of student-centered classroom teaching methods based on interactive learning and discovery concepts (Danker, 2015). In spite of this, most teachers in developing countries, especially Africa, still prefer and use the teacher-centered approaches in presenting chemistry concepts to learners (Danker, 2015). Even though the teacher-centered approach may be suitable when dealing with students with a very high intelligence level, Farmer (2018) argued that it can be problematic for weaker students who may be struggling to understand the concept(s) taught in class. In the teacher-centered approaches, the passive students rely on learning by listening, memorizing, and on the repetition of the taught knowledge, which has resulted in the major shortcoming of "passive learning" where students only have a short-term recollection of the concepts taught. This means that such students achieve a low level of thinking skill. According to Kurt (2017), to attain a higher and conceptual level of thinking, students need to take responsibility for their own learning and become active knowledge seekers. The student-centered learning approach however, emphasizes engaging learners to structure their learning to include applying their current class work or experience when they collaborate to solve problems, and make sense of their learning (Shih, 2017). One of the popular student-centered learning approaches is the Flipped Classroom Instructional Approach (FCA).

Flipped instruction or a flipped classroom is a kind of blended learning in which students learn new content online by watching video lectures, usually at home, and what used to be homework (assigned problems) is now done in class with teachers offering more personalized guidance and interaction with students, instead of direct teaching (Nwosisi et al., 2016). This approach uses class time for a variety of active-learning techniques, or techniques that require the students to vigorously engage in his or her own meaningful learning activities with little assistance from the teachers (Almodaires et al., 2019). The lecture content is then moved outside of the regular class 
period and often delivered through electronic means. Class activities, combined with online videos or other out-of-class activities, provide learners with multiple ways of learning course material (Jafarigohar et al., 2019).

The concept of hydrocarbons especially, naming of organic compounds using rules by the International Union of Pure and Applied Chemistry (IUPAC) is one of the more difficult chemistry topics, yet has been a compulsory one for pre-service science teachers in the colleges of education at the University of Cape Coast chemistry curriculum in Ghana for some time now. Several studies (Lo et al., 2017; Hew and Lo, 2018; Chen et al., 2018) have indicated that FCA is more effective in improving learners' performance in difficult scientific concepts than the traditional lecture method of teaching. Since the concept of IUPAC nomenclature of hydrocarbons was difficult for pre-service science teachers to understand; this study sought to adopt the FCA to teach the concept of IUPAC nomenclature of aliphatic hydrocarbons with the intention of improving pre-service science teachers' performance as well as their conceptual understanding of the concept.

\section{LITERATURE REVIEW}

Ozdamli and Asiksoy (2016) defined the flipped classroom instruction simply as an approach to learning in which what is traditionally done at school is done at home and homework which is traditionally done at home is completed in the class. FCA as an instructional practice was introduced in 2004 as an intervention for students who had missed classes for various reasons (Xie and Yang, 2015). In the study, the typical inclass instruction was recorded and posted to students to view outside the normal class hours and students did assignments that followed. The assignments were discussed during the in-class period. Subsequently, this approach has developed into the current model flipped classroom instruction. FCA can be adapted and modified to specific contexts (Ouda and Ahmed, 2017). According to Jafarigohar et al. (2019), the flipped classroom instruction is made up of four different pillars which must be taken into consideration during its implementation. The pillars have been abbreviated as "Flip" which is interpreted as:

1. Flexible Environment: Flipped learning provides various learning activities; teachers usually readjust their classroom environment in order to support either group work or individual practice. Consequently, students are allowed to choose when and where to view the videos and be more flexible in their own learning. As a result, learning goals are achieved in greater depths and more opportunities are provided for learning (Ouda and Ahmed, 2017).

2. Learning Culture: Learning culture advocates a learner-centered learning culture. In the traditional classrooms, the teacher was considered the "sage on the stage" (Shipton, 2014). This means that the teacher was considered the custodian of knowledge and information. By contrast, the flipped classroom intentionally readjusts the instruction from a teacher-centered approach to a learner-centered approach. Consequently, students are actively engaged in the construction of knowledge as they are engaged in their own learning and evaluate their learning dynamically and meaningfully which in turn has its own personal satisfaction.

3. Intentional Content: Intentional content accounts for the decisions that need to be taken by the teacher in a flipped classroom (Ouda and Ahmed, 2017). This pillar aims to increase classroom time to pave the way for studentcentered active learning strategies, depending on grade level and subject matter (Ouda and Ahmed, 2017).

4. Professional Educator: Here, the teacher's role seems to be more demanding and important in a flipped classroom than the one in the traditional classes. Teachers constantly observe their students, evaluate their work and give them feedback (Ouda and Ahmed, 2017). This pillar stresses the importance of teachers in flipped classrooms although their role is less visible (Ahmed, 2016).

The root of flipped learning lies in social constructivism. The foundation of social constructivist theory is based on a Vygotsky's "Zone of Proximal Development" (Vygotsky, 1978). Vygotsky assumed that whenever a student is at the zone of proximal development for a specific task, providing the suitable support will give the student sufficiency of a "boost" to accomplish the task. Once the student, by the virtue of support, becomes skilled at the task, support can then be removed and the student will then be proficient enough to accomplish the task once again completely on his own. The flipped learning is deeply connected to problem solving, active learning, inquiry learning, and interpersonal communications. Flipped classroom supports students to learn new knowledge that is required to be connecting to past learning, by doing this the students have to reconstruct their view of the world. They communicate with their peers in the classroom that eventually generate deeper learning. The process of learning as Vygotsky rationalises it, is obvious.

Vygotsky, in addition, considers interaction with peers as a successful means of developing skills and strategies. In a study such as this, it is crucial to adopt a tried and tested framework to identify gaps in the literature to provide a rationale for the research question(s) under investigation (Kerres and Bedenlier, 2020). Flipped learning has become popular in high schools and universities because of their ability to combine learning theories once thought to be incompatible-active, problembased learning activities founded on a constructivist ideology and instructional lectures derived from direct instructional methods founded on behaviorist principles (Turan and AkdagCimen, 2020).

Chemistry education (or chemical education) refers to the study of the teaching and learning of Chemistry in our schools, colleges, and universities. Topics in chemistry education might include understanding how students learn chemistry, how best to teach chemistry, and how to improve learning outcomes by changing teaching methods and appropriate 
training of chemistry teachers, in our schools and classrooms. Chemistry forms an integral part of the colleges of education under University of Cape Coast Science Curriculum as both core and elective subjects. At the college of education level, it is often called "General Chemistry" which is an introduction to a wide variety of fundamental concepts that enable the preservice teacher trainees to acquire tools and skills useful at the advanced levels, whereby chemistry is invariably studied in any of its various sub-disciplines. Among the many objectives of chemistry education in the colleges of education, include consolidating the chemistry trainees have learnt at various pre-tertiary schools they attended, it also helps pre-service teachers appreciate the beauty of the subject in explaining nature as well as promoting the pre-service teachers' conceptual understanding and develop their skills necessary to successfully endure future learning of chemistry.

Chemistry as a subject or course of study is considered difficult and challenging by most students and hence learning and understanding of IUPAC nomenclature of hydrocarbons may depend more on the teaching approach and the guiding principles or rules to follow. Chemistry students often find it difficult to comprehend the related chemical equations, formulae, and symbols. The concept of IUPAC nomenclature of hydrocarbon is at the symbolic level and therefore makes learning difficult for most students including pre-service teachers in the colleges of education. Kozma (2003) noticed that chemistry students' understanding is hindered by the surface features of representations, as these students see formulae of chemical substances (e.g., $\mathrm{CH}_{3}-\mathrm{CH}_{2}-\mathrm{CH}_{2}-\mathrm{CH}_{2}-$ $\mathrm{CH}_{3}$ or $\mathrm{CH}_{3} \mathrm{CH}_{2} \mathrm{CH}_{2} \mathrm{CH}_{2} \mathrm{CH}_{3}$ ) as a combination of letters and number rather than chemical formula (Taskin and Bernholt, 2014). The difficulty of some students in understanding chemical representations is also observed in an area where most of the chemistry students are unable to make translations among formulae (Wu et al., 2001).

The structure and naming of hydrocarbons, however, serve the basis for moving to similar tasks for organic compounds containing other functional groups. Naming and drawing of hydrocarbons, like all other chemical concepts at the symbolic level are associated with some degree of difficulty in learning with respect to their structures, equations, and chemical reactions. Sarkodie and Adu-Gyamfi (2015) stated emphatically that scientists cannot talk about IUPAC nomenclature relegating structural diagrams to the background. Difficulties faced by students in learning IUPAC nomenclature of hydrocarbons were found to be in two folds. These were the:

1) Ability to write the structural formula of an organic compound from its IUPAC name, and

2) Ability to write the IUPAC name of an organic compound from its structural formula.

Shriner et al. (2003) also pointed out that the ability of Chemistry students to translate the IUPAC name of an organic compound into its structural formula is the most important and most flexible as compared to the ability of Chemistry students to give the IUPAC name of any given structural formula. Moreover, Gillette (2004) was emphatic about the fact that when students are able to learn, apply, and interpret these three aspects very well, they can name any given organic compound with ease. The purpose of this study was, therefore, to improve Foso College of Education (FOSCO) pre-service science teachers' performance in IUPAC nomenclature of aliphatic hydrocarbons using FCA. Specifically:

Research Question: Are there any differences in performance among pre-service science teachers before and after exposure to the FCA to the IUPAC nomenclature of aliphatic hydrocarbons?

\section{METHODOLOGY}

The design employed in this study was a single group pre- and post-test action research design. This was because the study sought to solve a specific challenge faced by pre-service science teachers with regards to naming and writing IUPAC nomenclature of hydrocarbons mainly alkanes, alkenes, and alkynes through the use of FCA as an intervention strategy. The challenge of naming and writing IUPAC nomenclature of hydrocarbons faced by pre-service science teachers motivated them to volunteer to take part in this study as this study was conducted to improve their conceptual understanding and performance in IUPAC nomenclature of aliphatic hydrocarbons. The researchers therefore worked collaboratively with the pre-service science teachers by developing flipped classroom lessons on IUPAC naming of aliphatic hydrocarbons. Action research was appropriate for the intact or census class of level 100 pre-service science teachers who were already in an organized group. In the areas of instruction and content delivery, action research design encourages positive attitude toward learning and continuous performance improvement (Cohen et al., 2007). This study targeted improving pre-service science teachers' performance and conceptual understanding in nomenclature of aliphatic hydrocarbons (Goodnough, 2010) collaboratively as a major part of the study. The study used quantitative method to collect and analyzed data from two tests, "Pre-Service Science Teachers' Hydrocarbon Concept Diagnostic Test” (PTHCDT) and "Pre-Service Science Teachers' Hydrocarbon Concept Achievement Test" (PTHCAT) to verify how effective the FCA would be in enhancing the pre-service science teachers' performance in naming structures of aliphatic hydrocarbons.

\section{Sample and Sampling Procedure}

There are 16 colleges of education affiliated to the University of Cape Coast in Ghana but only one college was randomly selected for the study. The simple random sampling procedure was used to select only one of the 16 colleges of education. In the process, the first author listed all the 16 colleges of education affiliated to the University of Cape Coast and assigned numbers to each of the 16 individual colleges and then used table of random numbers and the Microsoft excel. As a result, FOSCO was selected. At FOSCO, there are 3-year groups of pre-service science teachers: the 100-level, 
200-level, and 300-level. The target group for the study was the 100-level pre-service science teachers as the concept of IUPAC nomenclature of hydrocarbons was taught at this level as a compulsory chemistry course. As stated, the naming of hydrocarbons following IUPAC rules has been found to be difficult and confusing to most of the pre-service science teachers, even though it is a compulsory chemistry course for all the 100-level pre-service science teachers. It should be noted that while these 100-level pre-service science teachers had some background knowledge of organic chemistry from their previous senior high schools (SHS); however, they had yet to learn the IUPAC nomenclature. A total of 45100 -level preservice science teachers took part in the study. The participants consent was sought and they voluntarily participated in the study. The 45 pre-service science teachers were made up of 36 males representing $80.0 \%$ and nine females representing $20.0 \%$. The ages of the respondents ranged between 20 and 28 years, with an average age of 24 years.

\section{Research Instruments}

In all, 9 weeks were used for the study. Out of the 9 weeks, 2 weeks were used for pre-intervention activities; 5 weeks were used for the flipped intervention activities ( 3 weeks online study; and 2 weeks face-to-face interaction in the classroom), and finally, 2 weeks were used for the post-test activities. Each lesson lasted $60 \mathrm{~min}$ and there were two lessons per week. The diagnostic and achievement tests used were in two sections consisting of 20 test items. In section "A," the five multiple choice test items covered Alkane, Alkene, and Alkyne, and these pre-service science teachers were asked to choose the correct option. Any correct option selected attracted one mark. In section "B," the test items consisted of three questions in the form of line angle structures, provided with 15 fill-in-theblank spaces to be completed. The test items which consisted of branched and substituted-chains of aliphatic hydrocarbons, focused more on pre-service science teachers' ability to apply IUPAC rules carefully in giving the parent or family names, types, and positions of functional groups as well as the types and positions of attached substituent, which are considered the most important rules for naming and writing IUPAC nomenclature in any organic compounds. 60 min duration was assigned to the tests and each correct response attracted one mark with the range of scores from 0 to 20 . The purpose was to assess pre-service science teachers conceptual understanding applying IUPAC rules in naming nomenclature of aliphatic hydrocarbons. The scoring of the aforementioned PTHCDT and PTHCAT were done using the following criteria:

(a) Options: the correct option identified by the pre-service teachers in section " $\mathrm{A}$ " attracted one mark.

(b) Structural identification: correct parent name assigned to the compound, type of functional group, position of functional group, type of substituent attached to the structure and position of substituent scored one mark each in section "B."

The instruments were pilot-tested by the third author, with preservice science teachers at St. Ambrose College of Education, who possessed similar characteristics to their counterparts at FOSCO. This was done to help identify those items which were too difficult or too easy for further moderation and improve on the internal consistency of the instruments. The reliability index for the PTHCDT and PTHCAT were determined using Cronbach reliability coefficient 20 and found to be 0.75 and 0.78 , respectively; which were considered appropriate for use as explained by Borg et al. (1993). Examples of both PTHCD and PTHCAT are shown in Appendices I and II.

\section{Data Collection Procedure}

The first author discussed with the tutors (second and third authors) who were the first author's students and were tutors at FOSCO and St. Ambrose, respectively, of our intent to conduct research with the pre-service science teachers from the sampled college where the second author was tutoring. The tutors were briefed on the task involving nature of what we intended to do and what our roles would be during the period of the study. On agreement and mutual understanding, the first author met the principal of FOSCO and sought permission to conduct the study in the college. The meeting and the discussion thereafter were fruitful and the principal then introduced the authors to the other members of the Science Department who also assured of their support and cooperation. The sampled preservice science teachers in the intact class were later informed about the purpose of the study, the study timeline, place, as well as assurances of confidentiality and protection of their identity. Data collection was done in three stages namely preintervention, intervention, and post-intervention stages and all these three stages were discussed with them.

At the pre-intervention stage, the first and second authors interacted with the pre-service science teachers for $1 \frac{1}{2}$ weeks instead of the planned 2 weeks due to the COVID-19 restrictions. Compilation of data for the study coincided with the worldwide pandemic of COVID, and therefore, data were seriously affected. The initial interaction, however, showed that even though the pre-service teachers have had background knowledge on organic chemistry from their SHS, they could not answer questions on naming and writing of structural, condense, and line-angle formulae of alkanes, alkenes, and alkynes. After this interaction, the idea of helping the preservice teachers to improve on their performance in naming structures of IUPAC nomenclature of aliphatic hydrocarbons was conceived. The second author then gave the PTHCDT on alkanes, alkenes, and alkynes to the pre-service science teachers in an intact class to solve. The results of the pre-test were scored. The analysis of the scores of the pre-service science teachers results in the pre-test showed that the preservice teachers, like many other pre-service teachers at that level have difficulties in naming and writing of structural formulae of aliphatic hydrocarbons. It was then necessary to adopt the FCA to enhance the pre-service teachers' performance on the concept of IUPAC naming of aliphatic hydrocarbons.

The intervention stage saw the implementation of the FCA which took the form of out-of-class online lessons combined 
with in-class face-to-face lessons. During the out-of-class online studies, lecture notes, resource materials, and internet links as well as relevant information on naming and writing the IUPAC nomenclature of alkanes, alkenes, and alkynes were packaged in the form of slides and lecture videos and sent to pre-service science teachers via WhatsApp platform created for the class. Pre-service science teachers then engaged in the learning at home by watching the videos and read the materials at their own convenient time. However, exercises and assignment on every lesson were added to the videos for pre-service teachers to answer within a given period of time and posted back the responses to the researchers to mark. The WhatsApp platform encouraged both researchers and pre-service teachers engaged in friendly and flexible chat where comments, contributions, suggestions and guiding principles were posted to help preservice teachers do corrections. The online-WhatsApp activities helped the pre-service science teachers to learn the concept IUPAC nomenclature of alkanes, alkenes, and alkynes ahead of time (when the COVID-19 lockdown was in session) at home, did exercises, and carried out homework activities as a form of active learning at their own pace. During the face to face in-class lessons (after the COVID-19 lockdown was lifted), pre-service science teachers came to class prepared to participate in more interactive and higher-order activities such as; solving more problems on writing and naming alkanes, alkenes, and alkynes by the IUPAC rules, engaged in class discussions and debates. Such collaborative discussions helped clarified misconceptions and difficulties they still had, whilst the researchers constantly evaluated pre-service science teachers work and gave them feedback.

In the post-intervention stage, the PTHCAT was administered to the pre-service science teachers to assess whether there had been any conceptual change after the implementation of the FCA at the intervention stage of the design. The pre-service teachers' responses in the post-test were scored and analyzed.

\section{Data Analysis}

Data from the tests, PTHCDT and PTHCAT, were analyzed quantitatively using descriptive statistics namely frequency and percentages. Statistical Package for Social Science version 20.0 for window was used for data analysis; and Microsoft excel program was used to present the data pictorially into Tables, bar-charts and pie charts.

\section{FINDINGS}

Table 1 shows a comparative representation of the preintervention and post-intervention test scores of the pre-service teachers' performance in the IUPAC nomenclature of aliphatic hydrocarbons namely alkanes, alkenes and alkynes.

Data in Table 1 shows that only 11 pre-service science teachers representing $24.4 \%$ passed the pre-test by having scores of 10 marks and above whereas as many as 34 pre-service science teachers representing $75.6 \%$ failed the same pre-test by having scores below 10 marks. The poor performance of the 45 pre-service science teachers exhibited in the pre-test scores in Table 1 have been presented pictorially in a pie-chart as shown in Figure 1.

On the other hand, as many as 37 pre-service science teachers representing $82.2 \%$ passed the post-test by having scores of ten marks and above whereas only eight pre-service science teachers representing $17.8 \%$ failed the same post-test by having scores below ten marks. The improved performance of the 45 pre-service science teachers exhibited in the post-test scores in Table 1 have been presented pictorially in a pie-chart as shown in Figure 2.

The entire 45 pre-service science teachers' pre- and post-test scores in Table 1 have been compared and are presented pictorially in a bar-chart as shown in Figure 3.

\begin{tabular}{|c|c|c|c|c|}
\hline \multirow[t]{2}{*}{ Marks } & \multicolumn{2}{|c|}{ Pre-test scores } & \multicolumn{2}{|c|}{ Post-test scores } \\
\hline & Frequency & Percentage & Frequency & Percentage \\
\hline 0 & 9 & 20.0 & 0 & 0.0 \\
\hline 1 & 6 & 13.3 & 0 & 0.0 \\
\hline 2 & 2 & 4.4 & 0 & 0.0 \\
\hline 3 & 3 & 6.8 & 0 & 0.0 \\
\hline 4 & 2 & 4.4 & 0 & 0.0 \\
\hline 5 & 4 & 8.9 & 0 & 0.0 \\
\hline 6 & 3 & 6.8 & 1 & 2.2 \\
\hline 7 & 2 & 4.4 & 1 & 2.2 \\
\hline 8 & 1 & 2.2 & 4 & 8.9 \\
\hline 9 & 2 & 4.4 & 2 & 4.4 \\
\hline 10 & 2 & 4.4 & 1 & 2.2 \\
\hline 11 & 1 & 2.2 & 3 & 6.8 \\
\hline 12 & 3 & 6.8 & 5 & 11.1 \\
\hline 13 & 2 & 4.4 & 4 & 8.9 \\
\hline 14 & 1 & 2.2 & 4 & 8.9 \\
\hline 15 & 2 & 4.4 & 7 & 15.5 \\
\hline 16 & 0 & 0.0 & 2 & 4.4 \\
\hline 17 & 0 & 0.0 & 4 & 8.9 \\
\hline 18 & 0 & 0.0 & 2 & 4.4 \\
\hline 19 & 0 & 0.0 & 2 & 4.4 \\
\hline 20 & 0 & 0.0 & 3 & 6.8 \\
\hline Total & 45 & 100 & 45 & 100 \\
\hline
\end{tabular}

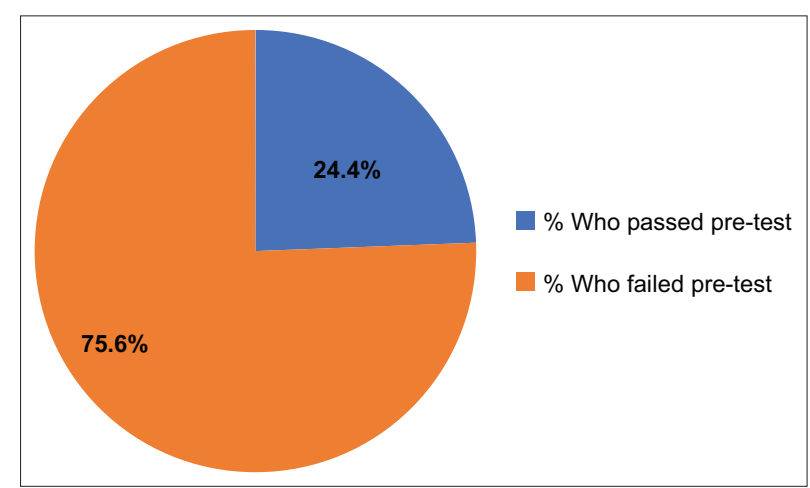

Figure 1: Percentage of pre-service science teachers who passed or failed pre-test 


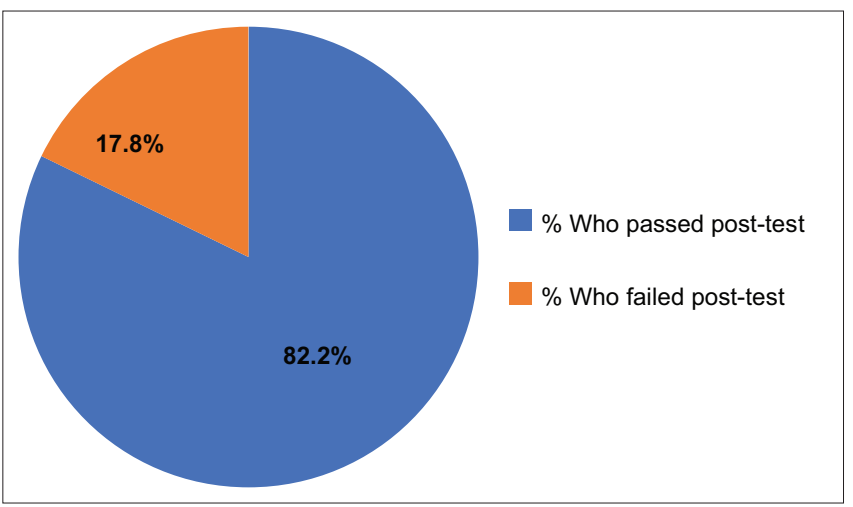

Figure 2: Percentage of pre-service science teachers who passed or failed post-test

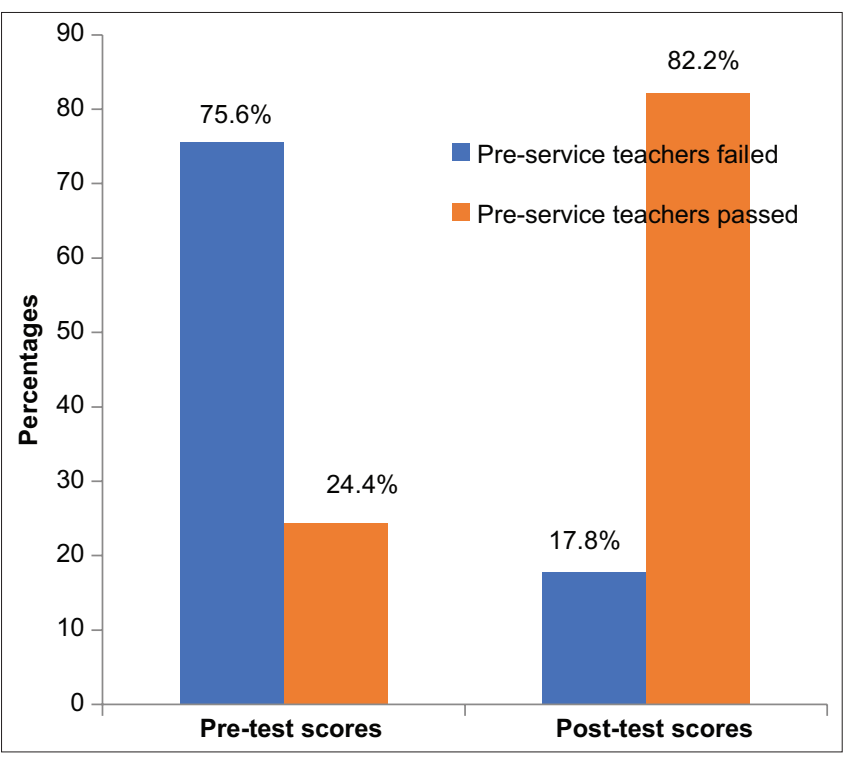

Figure 3: Comparing pre-service science teachers' pre- and post-test scores in percentage

The analyses in Table 1 and Figure 3 show that pre-service science teachers performed better in the post-test scores after the implementation of the FCA intervention activities than in the pre-test scores (i.e., before the implementation of the FCA intervention activities). This improved performance of the pre-service science teachers might be attributed to the FCA intervention activities used in the teaching and learning of IUPAC nomenclature of aliphatic hydrocarbons namely alkanes, alkenes and alkynes during in and out of the college activities.

\section{DISCUSSIONS AND CONCLUSIONS}

The result of this study revealed that pre-service science teachers' performance in the post-intervention test was far better than that of pre-intervention test. This means that preservice science teachers' performance had improved greatly after they have been exposed to FCA intervention activities. As indicated in Figures 1-3, 11 pre-service science teachers representing $24.4 \%$ got the pass mark in the pre-intervention test as against 37 pre-service science teachers representing
$82.2 \%$ who passed the post-intervention test. This can be attributed to the fact that the FCA intervention activities were very effective in improving performance as well as the conceptual understanding of the pre-service science teachers in the IUPAC nomenclature of aliphatic hydrocarbons namely alkanes, alkenes and alkynes.

This finding is in support with the results of (Seery, 2015; Lo et al., 2017; Hew and Lo, 2018; Chen et al., 2018; Xiu et al., 2019) that FCA was effective in improving learners' performance in scientific concept than traditional lecture method of teaching. Again, this study's results supported several other studies' results that used the flipped classroom instruction and found it effective in different countries and different course contents beyond Ghana. In her study, Fautch (2015) used lecture slides, exams, quizzes and a comprehensive final exam to measure the effectiveness of the flipped instruction and reported improvements in overall students' performance and comfort level in problem-solving for the flipped organic chemistry classes. Furthermore, Ojennus (2016) examined the learning gains between a flipped and a traditional lecture classroom for her upper division biochemistry course students at Whitworth University and found that the flipped format of instruction appeared to have higher learning gains. Tawfik and Lilly (2015), in another case study that included 24 undergraduate students from a University located in the Midwestern portion of the United States, found that students felt highly motivated and reported improvements in selfefficacy as a result of the flipped classroom environment.

As this study's results are consistent with the results of the aforementioned studies in the area of students' academic improvement using the flipped classroom instruction at different setting, it is enough to suggest that the flipped classroom instruction is effective in teaching other science disciplines irrespective of the level and geographical location. In the context of colleges of education in Ghana, the FCA has further shown its effectiveness in improving pre-service science teachers' performance and conceptual understanding in nomenclature of aliphatic hydrocarbons. The outcome of this study additionally demonstrates to the fact that using innovation instructional approaches such as the FCA, which combined the class activities with online lecture videos illustrations provided pre-service science teachers with multiple ways of learning course materials and can be applicable in other science disciplines thereby making science classes more interactive or reduce boredom as revealed in literature. The distinctiveness of the flipped classroom instruction was manifested in this study as the learning pattern of the pre-service science teachers was that of scaffolding where no pre-service science teacher was left out in this learning process; because every one of them was actively engaged in individualized learning and peer group learning, ensured collaborative support towards problem solving to achieve the set objectives.

The FCA was highly effective in improving the performance of pre-service science teachers in FOSCO in the IUPAC 
nomenclature of aliphatic hydrocarbons (alkanes, alkenes, and alkynes). The initial pre-intervention test however, yielded low performance indicating that the conversional lecture method did not help the pre-service science teachers in naming and writing the IUPAC nomenclature of aliphatic hydrocarbons (alkanes, alkenes, and alkynes). The FCA however, laid a good foundation for the pre-service teachers in developing individualized approach to learning, collaboration with peers and friends in a more positive interactive manner that resulted in their improved performance in the post-intervention test. The outcome of this study even though was a peculiar challenge facing pre-service teachers in FOSCO, tutors in other colleges of education in Ghana could consider the adoption and usage of effective teaching methods (e.g., FCA, activity-oriented methods, etc.) so as to help develop the preservice science teachers' conceptual understanding, improve their performance and also develop positive attitudes towards challenging chemical concepts such as IUPAC nomenclature of hydrocarbons in the colleges of education.

\section{REFERENCES}

Ahmed, H.O.K. (2016). Flipped learning as a new educational paradigm: An analytical critical study. European Scientific Journal, 12(10), 120-132.

Almodaires, A.A., Alayyar, G.M., Almsaud, T.O., \& Almutairi, F.M. (2019). The effectiveness of flipped learning: A quasi-experimental study of the perceptions of Kuwaiti pre-service teachers. International Education Studies, 12(1), 10-23.

Borg, W.R., Gall, J.P., \& Gall, M.D. (1993). Applying Educational Research: A Practical Guide. London, United Kingdom: Longman Publishing Group.

Chen, K.S., Monrouxe, L., Lu, Y.H., Jenq, C.C., Chang, Y.J., \& Chang, Y.C. (2018). Academic outcomes of flipped classroom learning: A metaanalysis. Medical Education, 52(9), 910-924.

Cohen, L., Manion, L., \& Morrison, K. (2007). Research Methods in Education. London, United Kingdom: Routledge.

Danker, B. (2015). Using flipped classroom approach to explore deep learning in large classrooms. The IAFOR Journal of Education, 3(4), 71-86.

Farmer, R. (2018). The what, the how and the why of the flipped classroom. Innovative Practice in Higher Education, 3(4), 14-31.

Fautch, J.M. (2015). The flipped classroom for teaching organic chemistry in small classes: Is it effective? Chemistry Education Research and Practice, 16(11), 179-186.

Gillette, M.L., (Ed.). (2004). Introducing IUPAC Nomenclature for Organic Chemical Compounds. Available from: http://www.cerlabs.com/ experiments/1053447599X.pdf

Goodnough, K. (2010). Teacher Learning and Collaborative Action Research: Generating 'knowledge-of-practice' in the context of science education. Journal of Research Science Teacher Education, 21, 917-936.

Hew, K.F., \& Lo, C.K. (2018). Flipped classroom improves student learning in health professions education: A meta-analysis. BMC Medical Education, 18(1), 1-12.

Jafarigohar, M., Haghighi, H., Khoshsima, H., \& Vahdany, F. (2019). Incorporation of flipped learning into EFL classrooms performance and perception. Iranian Journal of English for Academic Purposes, 8(3), 1-14.
Kerres, M., \& Bedenlier, S. (2020). Systematic Reviews in Educational Research. Berlin, Germany: Springer.

Kozma, R. (2003). Material features of multiple representations and their cognitive and social affordances in science. Learning and Instruction, 13(2), 205-226.

Kurt, G. (2017). Implementing the flipped classroom in teacher education: Evidence from Turkey. Educational Technology and Society, 20(1), 211-221.

Lo, C.K., Hew, K.F., \& Chen, G. (2017). Toward a set of design principles for mathematics flipped classrooms: A synthesis of research in mathematics education. Educational Research Review, 22(6), 50-73.

Nwosisi, C., Ferreira, A., Rosenberg, W., \& Walsh, K. (2016). A study of the flipped classroom and its effectiveness in flipping thirty percent of the course content. International Journal of Information and Education Technology, 6(5), 48-51.

Ojennus, D.D. (2016), Assessment of learning gains in a flipped biochemistry classroom. Biochemistry and Molecular Biology Education, 44, 20-27.

Ouda, H., \& Ahmed, K. (2017). Flipped learning as a new educational paradigm: An analytical critical study. European Scientific Journal, 12(10), 417-444.

Ozdamli, F., \& Asiksoy, G. (2016). Flipped classroom approach. World Journal on Educational Technology, 8(2), 98-103.

Paristiowati, M., Fitriani, E., \& Aldi, N.H. (2017). The effect of inquiryflipped classroom model toward students' achievement on chemical reaction rate. In: Application Infrastructure Provider (AIP) Conference Proceedings. pp. 1-6.

Sarkodie, P.A., \& Adu-Gyamfi, K. (2015). Improving students' performance in naming and writing structural formulae of hydrocarbons using the ball-and-stick models. Chemistry: Bulgarian Journal of Science Education, 24(2), 203-219.

Seery, M.K. (2015). Flipped learning in higher education chemistry: Emerging trends and potential directions. Chemistry Education Research and Practice, 16(4), 758-768.

Shih, W. (2017). Students' perception of a flipped classroom approach to facilitating online project-based learning in marketing research courses. Australasian Journal of Educational Technology, 33(5), 32-49.

Shipton, B. (2014). Sage on the stage or guide by the side? A proposed developmental pathway for police educators. Salus Journal, 2(1), 80-98.

Shriner, R.L., Hermann, C.K., Morrill, T.C., Curtin, D.Y., \& Fuson, R.C. (2003). The Systematic Identification of Organic Compounds. New Jersey, United States: John Wiley \& Sons Publishers.

Taskin, V., \& Bernholt, S. (2014). Students' understanding of chemical formulae: A review of empirical research. Journal of Science Education, 36(12), 157-185.

Tawfik, A.A., \& Lilly, C. (2015). Using a flipped classroom approach to support problem-based learning. Technology, Knowledge and Learning, 20(3), 299-315.

Turan, Z., \& Akdag-Cimen, B. (2020). Flipped classroom in English language teaching: A systematic review. Computer Assisted Language Learning, 33(5-6), 590-606.

Vygotsky, L.S. (1978). Mind in Society: The Development of Higher Psychological Processes. Harvard University Press.

Wu, H.K., Krajcik, J.S., \& Soloway, E. (2001). Promoting understanding of chemical representations: Students' use of a visualization tool in the classroom. Journal of Research in Science Teaching, 38(7), 821-842.

Xie, Y., \& Yang, Y. (2015). Research on the construction of flipped classroom teaching model of analytical chemistry. International Journal on Information Engineering for Mechanics and Materials, 3(5), 9-15.

Xiu, Y., Moore, M.E., Thompson, P., \& French, D.P. (2019). Student perceptions of lecture-capture video to facilitate learning in a flipped classroom. TechTrends, 63(4), 369-375. 


\section{APPENDIX I}

\section{Pre-Service Science Teachers' Hydrocarbon Concept Diagnostic Test (PTHCDT)}

Pre-Test

Purpose: This pre-test seeks to find out your conceptual understanding of IUPAC nomenclature of hydrocarbons before the FCA intervention activities. This exercise is being conducted for research purposes only; and because of this, marks obtained on the test will be treated confidentially. Thank you for your co-operation.

\section{BIO-DATA OF THE RESPONDENT}

Pre-service Science Teachers' Code.

Gender:

Male

Female

Age

Instruction: This test consist of two sections; the Section A \& B. For Section A, circle the correct option to each item and for Section B provide your candid answers in the spaces provided. Answer all the questions on this paper for 20 marks. Duration: 60 minutes.

\section{SECTION A - OBJECTIVE TEST ITEMS}

1. What is the IUPAC name for $\mathrm{CH}_{3} \mathrm{CHClCH}\left(\mathrm{CH}_{3}\right) \mathrm{CH}_{2} \mathrm{CH}_{2} \mathrm{Br}$ ?
A. 1-bromo-4-chloro-3-methylpentane
B. 5-bromo-2-chloro-3-methylhexane
C. 1-bromo-4-chloro-3-dimethylhexane
D. 5-bromo-3-chloro-3-methypentane

2. The IUPAC name for the hydrocarbon $\left(\mathrm{CH}_{3}\right)_{2} \mathrm{C}=\mathrm{CHCH}_{3}$ is:
A. 2-methy3-ene
B. 2-methylbut-2-ene
C. 2-methylpent-1-ene
D. 2-methylpent-2ene

3. Provide the IUPAC name of hydrocarbon shown below<smiles>CCC(C)=C(C)C</smiles>
A. 2 Methyl-3 ethylpropene
B. 2,3-Dimethylpent-2-ene
C. 2,3-Dimethylpent - 3-ene
D. 3, 4-Dimethylpent - 3-ene

4. What is the IUPAC name of the following compound?<smiles>CCC(C)CC</smiles>
A. 3-methylbutane
B. 1,1-diethylethane
C. 2,2-diethylethane
D. 3-methylpentane

5. What is the name of the compound $(\mathrm{CH} 3)_{2} \mathrm{CHCH}_{2} \mathrm{C} \equiv \mathrm{CH}$ ?
A. 4-methypent-1-yne
B. 1-methylpent-1-yne 
C. 4-methylpent-4-yne

D. 2,2-dimethylpent-1-yne

SECTION B -COMPLETE THE TABLE BELOW

\begin{tabular}{lccccc}
\hline Compound & Parent Name & Functional Group & $\begin{array}{c}\text { Position of } \\
\text { Functional Group }\end{array}$ & $\begin{array}{c}\text { Name of } \\
\text { Substituent }\end{array}$ & $\begin{array}{c}\text { Position of } \\
\text { Substituent }\end{array}$ \\
\hline 16 & 6 & 7 & 13 & 9 & 10 \\
& 11 & 12 & & & 14 \\
\hline
\end{tabular}

\section{APPENDIX II}

Pre-Service Science Teachers' Hydrocarbon Concept Achievement Test (PTHCAT)

Post-Test

Purpose: This pre-test seeks to find out your conceptual understanding of IUPAC nomenclature of hydrocarbons before the FCA intervention activities. This exercise is being conducted for research purposes only; and because of this, marks obtained on the test will be treated confidentially. Thank you for your co-operation.

\section{BIO-DATA OF THE RESPONDENT}

Pre-service Science Teachers' Code.

Gender:

Male

Female

Age

Instruction: This test consist of two sections; the Section A \& B. For Section A, circle the correct option to each item and for Section B provide your candid answers in the spaces provided. Answer all the questions on this paper for 20 marks. Duration: 60 minutes

\section{SECTION A - OBJECTIVE TEST ITEMS}

1. What is the IUPAC name for $\mathrm{CH}_{3} \mathrm{CCl}_{2} \mathrm{CH}\left(\mathrm{CH}_{3}\right) \mathrm{CHICH}_{3}$ ?
A. 2-Iodo-2,2-dichloro-3-methylpentane
B. 2,2-Dichoro-2-iodo-3-methylhexane
C. 2-Iodo-4,4-dichloro-3-dimethylhexane
D. 2,2-Dichloro-4-iodo-3-methypentane

2. The IUPAC name for the hydrocarbon $\left(\mathrm{CH}_{3}\right)_{2} \mathrm{CBrCH}=\mathrm{CH}_{2}$ is:

C. 2-Methy-2-bromobut-3-ene

D. 3-Bromo-3-methylbut-1-ene

C. 3,3-Dichloro-3-bromoprop-1-ene

D. 1-Bromo-1,1-dichloroprop-1-ene
3. $\mathrm{CH}_{3} \mathrm{CH}=\mathrm{CHCH}\left(\mathrm{CH}_{3}\right)_{2}$
C. 4,4-Dimethylprop-2-ene
B. 4-Methylpent-2-ene
C. 4-Methylpent-1-ene
D. 3, 4-Dimethylpent-3- ene

4. What is the IUPAC name of the following compound?

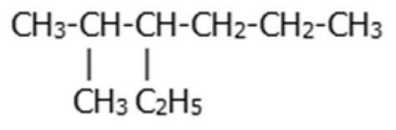



A. 3-Ethyl-4--methyl hexane
B. 2-Methyl-3-ethylhexane
C. 3-Ethyl-2-methylhexane
D. 4-Ethyl-5-methylhexane

5. What is the name of the compound $\left(\mathrm{CH}_{3}\right)_{2} \mathrm{CHC} \equiv \mathrm{CCH}_{3}$ ?

C. 4-methypent-1-yne

D. 4-methylpent-4-yne

C. 4-methylpent-2-yne

D. 2,2-dimethylpent-1-yne

\section{SECTION B -COMPLETE THE TABLE BELOW}

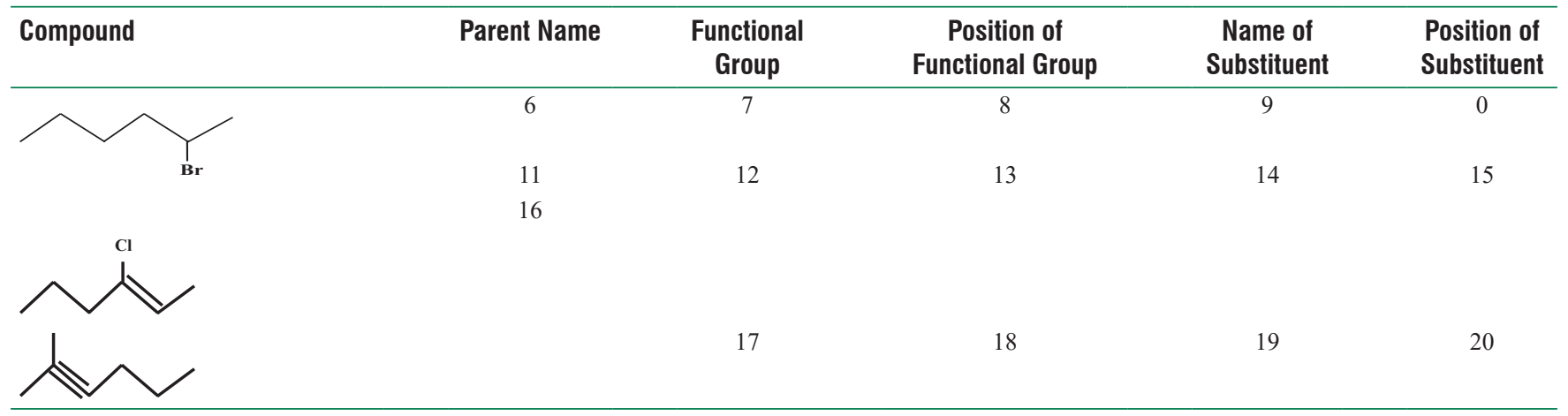

